\title{
HEALTHY AGEING IN SMART VILLAGES? OBSERVATIONS FROM THE FIELD
}

\author{
Lorna Philip ${ }^{1}$ and Fiona Williams ${ }^{2}$
}

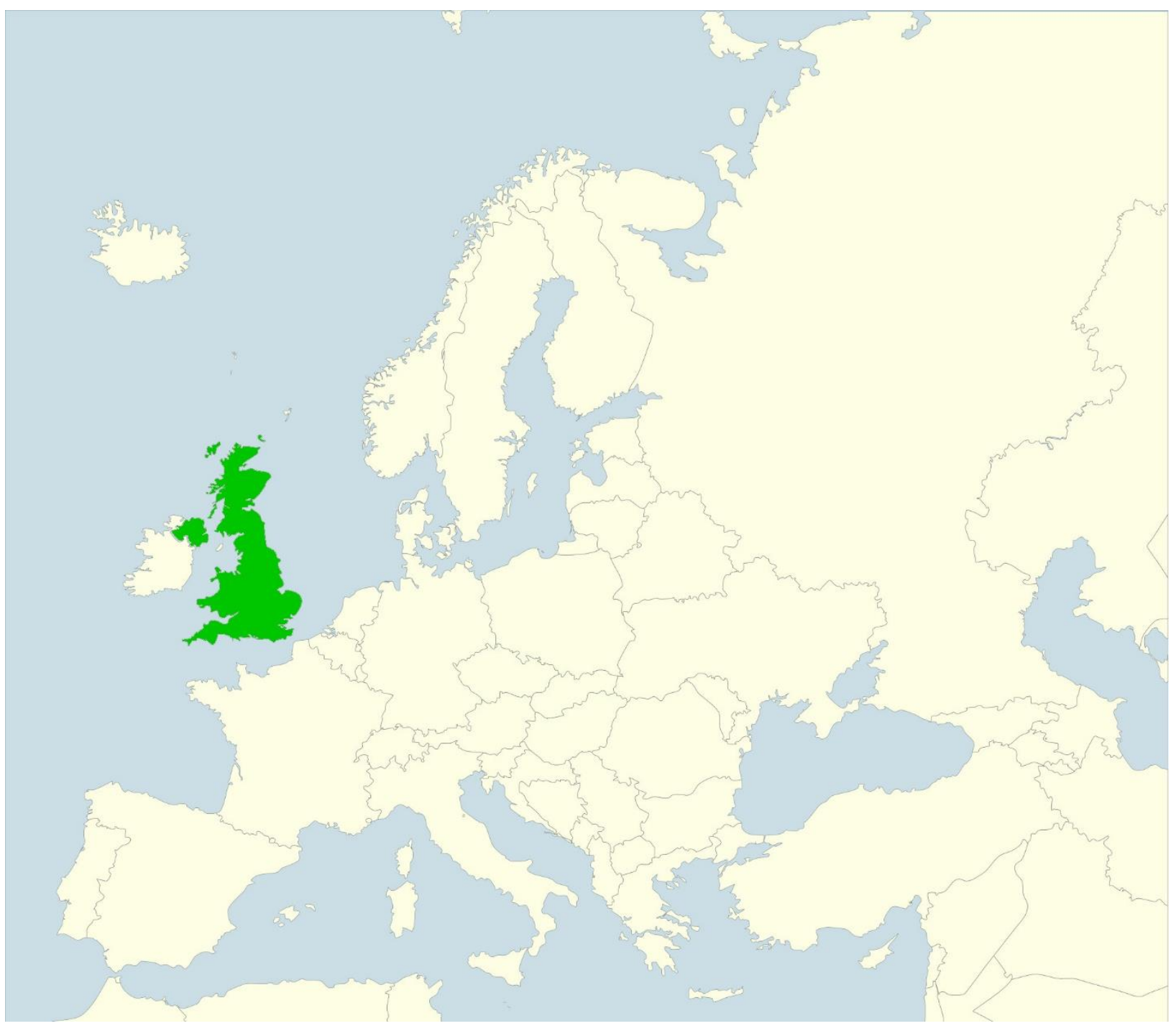

Department of Geography and Environment, School of Geosciences, University of Aberdeen. Email I.philip@abdn.ac.uk. ORCID 0000-0002-4788-2798.

2 Department of Geography and International Development, University of Chester. Email fiona.williams@chester.ac.uk. ORCID 0000-0002-7381-4350. 
Abstract: In the context of demographically ageing communities across rural Europe Smart Villages have considerable potential to promote ageing healthy. Whilst in principle supporting healthy ageing in the context of the Smart Village might appear a relatively straightforward endeavour, in operational terms, successful development of smart, $21^{\text {st }}$ century villages relies upon, and sometimes assumes, an appropriate interplay of socio-technological factors. Articulated through a lens provided by the digital ecosystem model advocated by the European Network for Rural Development (2018), this paper offers some observations from the field. We acknowledge the challenges faced by remote rural places in their journey to become 'smart places' and identify formal and informal interventions that could better position rural communities to become part of a wider, smart society.

Key words: Smart Villages; digital technologies; rural; demographic ageing; ageing well

\section{Introduction}

In 2017, the European Union introduced a new rural development policy concept, the EU Action for Smart Villages. The Smart Village vision is one where rural communities seize the initiative and drive forward solutions to existing and emerging challenges. Smart Village strategies, "go beyond isolated activities of individual local actors and aim instead to enable the community to jointly implement integrated packages of future-orientated actions" (European Network for Rural Development - hereafter ENRD - 2019a, p. 5). Action is grounded in the needs and contexts of specific rural communities and requires social innovation and new bottom-up ideas and initiatives.

Depopulation and the long-term outmigration of young adults have long been recognised as demographic challenges for rural Europe. Demographic ageing is an existing demographic process that will become more pronounced across rural Europe in the foreseeable future (Eurostat, 2019). Digital interventions have transformative potential as enablers of what the World Health Organisation (2019) describes as health ageing ${ }^{3}$ in rural and urban contexts. Smart Villages that successfully deploy digital solutions will be well placed to support healthy ageing for older rural citizens ${ }^{4}$, but, as we explore in this paper, what practical challenges need to be overcome to facilitate Smart Village solutions to demographic ageing challenges?

To further the agenda of realising ambitions to develop Smart Villages, the ENRD $(2018$, p. 35) proposed a five layered 'digital ecosystem'. This idealised model comprises four horizontal layers (society, digital services, technical platform and infrastructure) and a cross cutting vertical layer, the organisational ecosystem, see Figure 1. In this paper we utilise the digital ecosystem as a lens through which to interrogate findings collated from two completed and one ongoing research project. Focusing on the 'society' and 'digital services' layers we consider how everyday life and health and social care-related interventions used by older rural adults co-exist with digital technologies and are contingent upon them. We also consider how, in practice, the society and digital services layers interact and how this interface could be effectively supported through the organisational ecosystem. Taken together, our reflections allow us to offer suggestions as to how rural communities may develop their 'smart' ambitions to support older rural citizens to age well. By critically reflecting on our collated research findings and observations grounded in our personal experiences in the field we seek to inform, post hoc, the practicalities involved in the pursuit of digital technological solutions as an integral part of achieving a Smart Village vision. We conclude by articulating three barriers to digital solutions

\footnotetext{
3 The WHO (2019, no page numbers) defines Healthy Ageing as "the process of developing and maintaining the functional ability that enables wellbeing in older age. Functional ability is about having the capabilities that enable all people to be and do what they have reason to value. This includes a person's ability to: meet their basic needs; to learn, grow and make decisions; to be mobile; to build and maintain relationships; and to contribute to society".

${ }^{4}$ For the purposes of this paper 'older adults' are defined as those of an age to be eligible to receive a state pension.
} 
being deployed to address challenges associated with ageing in a Smart Village context offering new insights to relationships between rural ageing, the Smart Villages concept and wider ambitions to achieve sustainable rural communities.
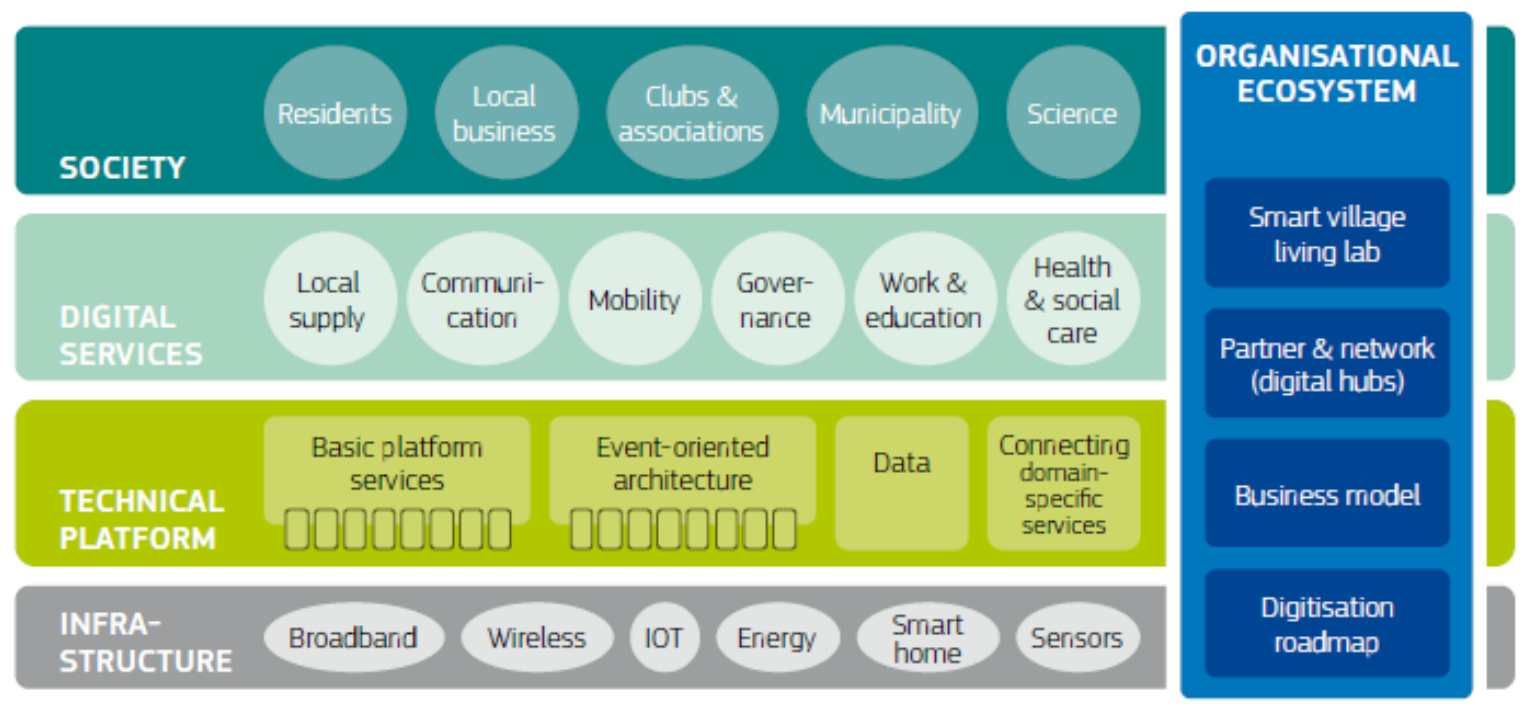

Source: Steffen Hess, Frounhofer IESE

Fig 1. A digital ecosystem for a smart village. Source: ENRD, 2018: 34

The paper is structured as follows. In the following section we outline the conceptual features of the smart discourse. Next we note key dimensions of demographic ageing and consider how 'smart rural' opportunities/ the deployment of digital technologies in rural contexts have been posited as a means to promote ageing well in rural places. Our case studies are then introduced before we reflect on our findings using the lens of the digital ecosystem layers. Our conclusions critically review findings from our case studies, highlighting opportunities and some challenges faced by remote rural places with ageing populations on a journey to become part of the smart, digital society.

\section{The notion of smart in a Smart Villages context}

Despite "ample potential for terminological fuzziness" (de Jong et al, 2015, p. 2) and the "somewhat evasive" (Nilssen, 2019) nature of the concept, the notion of 'smart' is undoubtedly gaining popularity in academic, lay and policy discourses. Discernible and related characteristics of smart narratives in academic and policy contexts include, for example: policyorientation framed in terms of sustainable development principles (c.f. Caragliu et al, 2011); attribution to notions of place - for example, smart cities (c.f. Ash et al, 2018; Caprotti and Cowley, 2018), smart rural (c.f. Naldi et al, 2015) and smart villages (European Commission, 2017; ENRD, 2018; Visvizi and Lytras, 2018); and recognition of a smart role for information and communication technologies. A popular configuration of the notion of smart is that it extends and actualises the digital promise of problem solving (Luque-Ayala, 2019) with commentators foregrounding the transformative potential of the digital. Soto and Nieto (2019, no page numbers) observe that "Smart Cities were originally conceived primarily in technological terms - big data, interoperability, artificial intelligence and the Internet of Things" as a means of transforming the ways in which cities function, but as the authors suggest this does not translate to conceptualisation of Smart Villages. Increasingly, technocratic dominance in the smart development discourse is challenged by those who argue that technology is not the defining feature of smart systems (c.f. Zavratnik et al, 2018) but merely an instrument in the pursuit of solutions to challenges (Angelidou, 2015). Thus, in a village context, the smart prefix implies a focus upon empowering local communities to engage with their future, including the 'smart' use (where appropriate) of digital technologies. 
Applications of smart growth and development concepts are intended, in practice, to support sustainable economic development (Caragliu et al, 2011; Naldi et al, 2015) or, conversely, to achieve smart shrinkage (Peters et al, 2018). The introduction of the smart discourse in a rural studies context was catalysed by the European Union in 2010 as it adopted the notion of 'smart' in its ten-year growth strategy, Europe 2020. Here priority was given to a smart growth economy based on knowledge and innovation, sustainable growth and inclusive growth. The logic behind this smart growth policy was critiqued by Naldi et al (2015) who concluded that smart is not a 'one size fits all' concept, its application requires a place-based approach that acknowledges the non-uniformity of rural areas; a point echoed by Zavratnik et al (2018) in their Smart Villages initiatives and practices review. Territorial sensitivity was acknowledged from the outset in the EU Action for Smart Villages (2017) which continues to adopt principles of endogenous development that have gained prominence in rural development policy over the last three decades.

While digital infrastructure and information and communication technologies (ITCs) maintain a central presence in theoretical frameworks underpinning research in the smart realm, academics and policy-makers alike are keen to point out that "the validity of any claim to be smart ought to be centred upon something more than the use of information and communication technologies alone" (de Jong et al 2015, p. 35). This is indeed the case within the context of the European Commission's 'Smart Villages' initiative where the emphasis at the outset was stated as being on people, rural communities, finding practical solutions to challenges and embracing opportunities which are potentially powered by digital solutions (ENRD, 2018). This careful positioning of digital communications, technologies, and innovations as 'tools' or 'means' to achieving desired outcomes is prudently set against the challenging backdrop of digital divide debates, recognised and profiled in the Cork Declaration (European Commission, 2016) and explored in detail in a swathe of academic literature. More recent examples elucidate, for example, how insufficient digital infrastructure (Philip et al, 2017) and lower and slower levels of uptake of digital developments are typically associated with peripheral rural regions (Salemink et al, 2017) and how combined these can create challenging environments for small rural businesses in sectors critical to the economic future of many remote and sparsely populated rural areas (Philip and Williams, 2019).

\subsection{The Smart Village concept}

Rural development policy across Europe has, over the past three decades, stressed the importance of action at the local scale and various policy measures (including LEADER and other forms of community led local development) have been funded under the expectation that they would support bottom-up proposals for development that reflect local contexts and priorities. The 2016 Cork 2.0 Declaration, A better life for rural areas, stated that the approach to rural development across Europe should emphasise "the potential of rural areas and resources to deliver on a wide range of economy, social and environmental challenges and opportunities benefitting all European citizens" (ENRD, 2019a, p. 1). Stemming from this declaration was the policy concept, the EU Action for Smart Villages, which was presented as a means by which local action across rural Europe could be encouraged and supported. Underpinning this new concept was a recognition that persistent rural challenges, such as depopulation and poor provision of public services sat alongside opportunities such as "the impact of existing and emerging digital technologies, the low-carbon and circular economies, the bioeconomy, new value chains, new patterns of mobility, closers links with cities and so on" (ENRD 2019a, p. 2). Smart villages ${ }^{5}$ would take the initiative themselves to develop solutions to the challenges they faced, making use of technology and social innovation to respond to persistent and new challenges and, by extension, improve quality of life and living standards.

\footnotetext{
5 The scale of Smart Villages is intentionally fluid, designed to allow what is meaningful in different local contexts to emerge as the territorial grouping around which an initiative develops. For example, Smart Village strategies could emerge at the level of discrete small settlements, municipalities, groups of municipalities or other spatial units such as an island. It is presumed, however, that a Smart Village strategy will start at the small scale and over time expand through cooperation with other geographical units.
} 
The use of existing and emerging technologies is not a prerequisite for the development of a Smart Village. However, digital technologies have been explicitly identified as an instrument by which rural communities can utilise existing strengths and develop new opportunities. For example, ambitions of the EU Action for Smart Villages would be achieved if "traditional and new networks and services are enhanced by means of digital, telecommunication technologies, innovations and better use of knowledge" (ENRD 2019, p. 3). Additionally, the definition of Smart Villages offered by the Pilot Project on Smart Eco-Social Villages (2019, p. 2) states that "Smart Villages are communities in rural areas that use innovative solutions to improve their resilience, building on local strengths and opportunities. They rely on a participatory approach to develop and implement their strategy to improve their economic, social and/or environmental conditions, in particular by mobilising solutions offered by digital technologies."

Despite acknowledging the need to tackle the three components of the digital divide, namely territorial inequalities in broadband infrastructure, uptake of digital services and digital skills and literature (c.f. ENRD, 2019b), somewhat paradoxically information and communication technologies continue to be championed in policy and regional development as ways in which the relative disadvantages of rurality can be overcome. As part of a Thematic Group (TG) remit for Smart Villages, the European Network for Rural Development focussed its attention on social and digital innovation in rural services, profiling innovative solutions for rural service provision, enhanced by developments in technology (ENRD, 2018). The promotion of "digital transformation of rural areas" is presented as a driver of 'Smart Villages', alongside "responding to depopulation and demographic change" and "financing local solutions to public funding cuts and the centralisation of public services" (ibid., p. 8). The potential of smart villages to promote active ageing and sustain independent living in later life is implicit within this TG: "Citizens need to be able to use digital technologies to their full potential and be able to recognise their added value for improving their quality of life. This is particularly true for rural communities with an ageing population" (Pilot Project on Smart Eco-Social Villages, 2019, p. 4). In demographically ageing communities, which includes many remote rural areas across Europe, eHealth technologies, smart homes and digital applications to facilitate social interaction have considerable potential to support individual and community wellbeing. This potential, and barriers to its successful realisation, is interrogated in sections that follow. Although we recognise that 'smart' and 'digital technologies' are not synonymous, for the remainder of this paper we adopt the premise that digital technology is an instrument pivotal in the realisation of Smart Village ambitions.

We now turn to outline key dimensions of demographic ageing and consider how 'smart rural' opportunities/ the deployment of digital technologies in rural contexts offer a means to promote healthy ageing in rural places.

\section{Demographic ageing and 'smart rural' opportunities}

Population ageing is a "dynamic bio-social process that fundamentally alters many aspects of society and the economy" (Philip et al, 2012, p. 58). Across Europe national populations are ageing, a consequence of medical and other health care advances leading to increased life expectancy, falling fertility rates and the ageing of successive post World War Two 'baby boom' cohorts. The proportion of the European population aged 65 and over was, in 2016, 19.2\% (Eurostat, 2017). Population ageing across Europe is not homogeneous at the national scale. For example, $13 \%$ of the Irish population in 2016 was aged 65 and over compared to $22 \%$ of the Italian population (ibid.). Sub-national patterns can be equally divergent, often being the outcome of historical and/or contemporary internal population redistribution. The rural areas of many European countries, the more remote and peripheral rural areas in particular, already have an older population profile than urban areas. In Scotland, for example, 2016 estimates reported that $24 \%$ of the remote rural population was aged 65 and over compared to only $16 \%$ in large urban areas. This urban-rural demographic pattern is projected to continue for the foreseeable future.

Rural demographic ageing poses many of the same challenges as ageing in an urban context. Increased demands on health and social care services, accessibility challenges arising from 
service restructuring, loneliness and limited opportunities for social interaction, for example, are place-independent challenges. However, characteristics of rural places such as sparse populations, a dispersed settlement structure with few sizeable population centres and inhospitable terrain add additional, place-based challenges to public, private and voluntary sector interventions and informal family and/or neighbourly efforts to promote the healthy ageing of older rural citizens.

Specific policies such as 'Ageing Well with Information and Communication Technologies' recognise that "digital technology can help older people to stay healthy, independent and active at work or in their community for longer" (European Commission, 2018b, no page numbers). The European Union and other bodies who fund research have supported many projects exploring different ways in which digital technologies could be deployed to address societal challenges associated with demographic ageing. An implicit assumption behind some developments is a desire to create financially sustainable solutions to the increasing cost of health and social care arising from an ageing population. Other developments are designed to support independent living, provide opportunities for social interactions and community engagement and give older adults choice and a greater sense of autonomy. These may all help to create conditions that support or enhance quality of life.

Digital technologies and applications, including those profiled in the Smart Villages digital ecosystem model, are already being deployed and have considerable potential to be more widely used in rural contexts, including to address some of the challenges of demographic ageing. For example, online shopping and online banking can help mitigate against private sector service providers no longer having a physical presence in many communities. Social media and other digitally supported communication platforms (e.g. Skype, Facetime) provide new ways in which older adults can keep in touch with communities of place, communities of interest and with friends and family who do not live nearby. Assisted living technologies, such as trip alarms, motion sensors or smart lighting can provide reassurance to family members that older adults remain safe and well at home. eHealth devices including blood pressure monitors that can transmit readings to a patient's medical professional or online consultations with specialists can reduce the need for older patients to make long distance journeys to attend medical appointments in person and can reduce costs of providing specialist health care to small, dispersed populations. Of potential benefit for all, some of these digital technology applications could be particularly useful in supporting in situ ageing for the large proportion, $32.1 \%$ in 2015 (Eurostat, 2017), of the European population aged 65 and over who live alone.

People of all ages can and do actively participate in the digital society. Based on responses to the Survey of Health, Ageing and Retirement in Europe (SHARE) König et al (2018) found that $49 \%$ of European adults aged 50 and over used the internet in the week before participating in the survey. Eurostat (2017) reported that across Europe, in $2015,45 \%$ of the population aged 65 and over used the Internet at least once a week although usage varied markedly at the national level (e.g. $80 \%$ in Sweden but only 13\% in Romania). For older Europeans drivers of private Internet use include "personal resources, prior experiences with technology, social salience as well as contextual influences" (König et al, 2018, p621). In the UK the proportion of retired adults classed as 'recent internet users' increased by almost $25 \%$ between 2011 and 2018 (Office for National Statistics, 2018). Although those aged 75 and over continue to be the least likely age group in the UK to use the Internet, the proportion of over $75 \mathrm{~s}$ who were 'recent internet users' rose from $20 \%$ in 2011 to $44 \%$ in 2018 (ibid.). The increase observed in the 65-74 age group was even more marked, growing from $52 \%$ in 2011 to $80 \%$ in 2018 . The UK's generation gap in Internet use will continue to contract as 65-74 years old Internet users grow older and it is conceivable that European nations where Internet use by older adults is currently low will follow the UK's experiences as time progresses.

Alongside the many opportunities digital technologies offer there remain challenges and barriers to be overcome before their full potential can be realised. These may be situated in any one of combinations of the four horizontal layers of the digital ecosystem. Successful operation and integration of the four horizontal layers (society, digital services, technical platform and infrastructure) is advocated by the ENRD (2018) to create a Smart Village ecosystem. Successful development of smart, $21^{\text {st }}$ century remote rural villages also relies upon 
an appropriate interplay of socio-technological factors including addressing underlying reasons for persistent digital divides. ENRD (2019b) listed three components of digital divides that need to be addressed to enable Smart Village aspirations to be achieved; broadband infrastructure, digital skills and literacy and promoting uptake of digital services. To this list we would add awareness of the costs to older adults of owning and using digital devices. As illustrated by our case studies, nuanced framings of older rural adults' attitudes towards digital technologies and their acceptability in various domains of life, help pinpoint weaknesses in the society and digital services layers of the digital ecosystem that require attention. We highlight challenges located within the infrastructure and technical platform layers, alongside suggestions as to how these can be mitigated.

\section{Methods}

The empirical base of this paper is findings from three research projects in which digital technologies as a means of supporting health and wellbeing amongst older rural populations have been explored. These serve as illustrative case studies though which potential means of successfully exploiting digital opportunities to support healthy ageing in the context of Smart Villages may be identified. They are also a lens through which barriers to exploiting the potential of smart developments to address rural challenges associated with demographic ageing may be interrogated. The territorial context of the three case studies is rural Scotland, Wales and England, of relevance because, in a European context, older adults in the UK have been early adopters of digital technologies. Lessons learnt from the experiences of older rural adults who have engaged with digital society could inform efforts elsewhere to deploy digital solutions to rural challenges such as ageing. Many rural areas of the UK struggle with poor Internet connectivity (c.f. Philip et al, 2015; 2017), a picture replicated in many European nations and in other advanced economies. Two of the three case studies draw upon research undertaken in remote rural areas where poor connectivity is frequently a barrier to effective digital engagement. Two of the three case studies are completed research projects, the third is, at the time of writing, a 'live' project. All three explore the role of digital technologies in the everyday lives and practices of older generations, which directly and indirectly support healthy ageing, and have focused on contexts that align with territorial units envisaged for Smart Villages. Each case study is now introduced in turn.

\footnotetext{
Technology for Older Adults: Maximising Personal and Social Interaction (TOPS)

Aim

To examine interactions between rural older adults suffering from chronic pain and their health and social care providers and to consider how new (eHealth) technology could play a part in enhancing life experiences.

Territorial context

Two remote rural settings, in Scotland and Wales.

Methods

1. Survey of members of Pain Association Scotland to find out how those living with chronic pain interacted with health and social care providers, used eHealth devices in the home and what their attitudes towards increased use of healthcare technologies in the future were.

2. Observations of interactions between older adults with chronic pain and their health and social care providers during a home visit, followed by separate interviews with the older adults and their health or social care professional during which their experiences of in-person care and use of e-Heath applications and their views about potential benefits and possible weakness of a health and social care model where more use was made of eHealth technologies were explored.

3. Semi-structured interviews with a small group of older rural adults who had completed an eHealth programme explicitly designed for chronic pain patients.

4. An affiliated PhD project explored how ICT could be used to 'bring the outside in', allowing older, housebound adults who lived in rural areas to remain connected with communities of interest and place and with their friends and families.

For further details see Corbett and Williams (2014); Currie et al (2015); Philip et al (2015); and Dowds et al (2018).
} 


\section{Rural Public Access WiFi Service (Rural PAWS) \\ Aim}

To explore how to enable digital inclusion in commercially 'hard to reach' areas without, or with less than acceptable, access to broadband services. Three objectives were: (i) to develop and test deployment of new access methods/services to provide commercially viable/lower cost Internet service provision that is acceptable to users in currently 'hard-to-reach' rural areas/communities; (ii) to understand and analyse the technological challenges and service requirements that need to be overcome to realise a very low cost service; and (iii) to explore the impact that use of the technology had on personal and business lives

Territorial context

A Broadband Development UK 'intervention area' in remote rural Shropshire, England.

Methods

Participants included existing Internet users and those with little or no previous experience of using the Internet to allow territorial and socio-economic digital exclusion to be explored. A rate-limited 6 satellite broadband service was installed at no cost to eight households which were home to twenty individuals, four of whom were older generation adults. Participating households took part in pre, mid and post satellite deployment interviews, completed Internet use diaries and were later interviewed for a 'one year on' follow up. Analyses of these data provided insights into the types of online activities different households and different age groups engaged with and what online opportunities were most valued by participants and why.

For further details see Williams et al (2016); Philip et al (2017) and Philip and Williams (2019).

\section{The Tribe Community Catalyst pilot (Tribe) \\ Aim}

To develop a place based digital facilitator of social action and active citizenship by creating a technological framework to strategically mobilise members of the public to aid, action and support vulnerable groups in society and in turn reduce pressure on public services to address the challenges of an ageing population, loneliness and inequality. The project endeavours to rethink micro-commissioning, social prescribing and social action to generate new paid and voluntary opportunities and improve quality of life for older people.

Territorial context

Three parishes in rural Shropshire, England.

Methods

A pilot-study within which procurement through a micro-commissioning arrangement with the Local Authority will be tested. 'Need' within communities will be mapped. Areas of high need will be strategically actioned through organised local citizen engagement, mobilising people across all ages and lifestyles to deliver, or benefit from, individual or collective activity, in ways that suit them. The pilot is a formal collaboration between Bronze Labs (the Tribe platform) and Community Catalysts. The latter is a UK tried and tested approach based on releasing people's capacity to care whose model scales through a single coordinator, or catalyst, support for up to 200 small, self-organising enterprises. It results in low-cost, flexible and personal care for older or disabled people and their families and self-employment for people who set up and run micro-enterprises. The Tribe platform provides the technology to enable the micro-commissioning of help and care from local people and support community capacity building.

For further details see Community Catalysts C.I.C. (2019); Gov.uk Digital Marketplace; Howells (2018); Tribe (2018).

From the TOPS and Rural PAWS case studies we present, post-hoc, illustrative examples of the use by older adults and service providers of various digital applications in everyday life contexts. We outline lessons to be learnt if digital barriers are to be overcome and smart actions deployed to support and promote healthy ageing well. The Tribe project is still in early stages of development. Characteristic of a 'living lab' it provides an opportunity to incorporate lessons

\footnotetext{
6 A 'rate limited' Internet connection is one where data upload and download rates are externally controlled. In the case of the Rural PAWS project download speeds were capped at $1.5 \mathrm{Mbit} / \mathrm{s}$, purposefully ensuring that it was not in direct competition with private satellite broadband providers. Access to 'whitelisted' sites, public sector websites with a 'gov.uk' domain name for example, was provided via a faster connection.
} 
learnt from previous research regarding the digital ecosystem's society - digital services interface and barriers to the design of an organisational ecosystem explicitly intended to enhance older people's access to services and their quality of life.

\section{The Smart Village digital ecosystem: applications and illustrations}

The society and digital services layers of the digital ecosystem model offer a framework within which dimensions of healthy ageing in rural places can be interrogated. We now profile these before highlighting opportunities and barriers to successful interactions between the layers, an interface that has to work if a functional organisational Smart Village digital ecosystem is to be developed.

\section{Profiling the 'society' layer}

ENRD (2018) articulate mastering the 'society' layer of the digital ecosystem in terms of including local residents and public and private stakeholder groups, from the outset, in any attempts to promote Smart Villages. In other words, the design and build of digital solutions must be based on locally defined needs. A Finnish government study that calls for "innovative solutions to providing services [...] identified through local experimentation" (ENRD, 2018, p. 35) is cited to illustrate this point. In many respects our case studies represent such experimentation and we draw upon our experiences in the field in the sub-sections that follow.

\section{Digital technologies will be used if they meet the needs of older adults}

Within the context of the TOPS and Rural PAWS case studies, the digital needs of ageing rural residents were examined. The circumstances of the older generations in each study differed significantly, as did the numbers of older people involved in the two research projects. Both projects illustrated a willingness on the part of participants to engage with digital technologies to meet self and externally defined needs. However, sensitivity to an individual's need was identified as being paramount in order to find means or incentives to encourage older residents to engage with what was considered a new world to them.

In the TOPS project, the motivation was a desire to improve the individual's health through the digital opportunities presented to them, crucially with sufficient health professional validation and support. For example, we interviewed an older rural adult with chronic pain who had attended a pain management course delivered in person to a group of patients. Subsequently this individual had been referred by their clinician to complete an on-line pain management course. We were told that the online course had been preferred, not because of the course content but because this participant had not liked being in a group setting, saying it was "Nothing to do with the people who were running it, [I] just didn't like being in amongst people ..." (Currie et al, 2015, p. 6). In this case an incentive to use an eHealth technology was being able to avoid interacting with other patients when participating in a health care intervention; digital technologies facilitated a personal preference being met (note, however, that some other participants favoured the in-person group mode of delivery over the eHealth mode).

In the Rural PAWS study, providing access to ICT infrastructure gave older adults an opportunity to 'give it a go'. Sufficient support to make Internet use both manageable and meaningful was a further incentive. One older generation participant told us, "It's a lot better than I expected it to be ... I'm enjoying it" (Williams et al, 2016 p. 769). Invariably this support was derived from proximate family members. Older resident participants in both of these projects were willing and enabled to digitally engage. This presents the question as to how to further encourage, harness and support older adults' motivation to engage with an array of digital technologies.

\section{Older adults often require support to use digital technologies}

The Rural PAWS participants included two older generation farming households, all members of which remained actively involved in the farm business. None had been digitally engaged before their participation in the research, yet all, to varying degrees, went on to use the Internet for browsing purposes - in relation to the farm business (e.g. weather reports, livestock sale 
reports), to satisfy wider farming and local community interests (e.g. local events, news), and to inform health issues. At the project end, all participants signed up to an Internet Service Provider (ISP). These activities were initially facilitated by younger family members who lived nearby, "We'll probably be picking [son's] brains to start with anyway," but as participants became more familiar with the technology, the involvement of nearby family members lessened to roles of technical 'trouble-shooting' or Internet tasks by proxy for financial transactions in particular, for example, farm business related administration, or on-line shopping. A reliance on 'known' others to strengthen digital skills in the initial phases of the project highlights a potential barrier to engagement by older adults in Smart Village initiatives. Digital literacy amongst older rural populations lags behind that of the population as a whole, especially amongst the over 75s. While our findings demonstrate that residents are often willing to engage, bespoke support was required. In the Rural PAWS project, informal digital literacy upskilling was suggested through the encouragement of peer support in pre-existing community fora and events, for example "iPad clubs or what they call them, just take your iPad to coffee ..." (see, Williams et al, 2015) which in turn was perceived as reducing reliance on family and neighbours.

\section{Striking a balance: are smart approaches appropriate substitutes for in-person approaches?}

The household and health circumstances of TOPS participants impacted upon digital utility and capability, both from health care provider perspectives and that of the older person. On the one hand, "New digital technologies offer a new means of engaging with activities which promote well-being. Many older adults are regular users of digital and Internet-enabled devices and they use these technologies to maintain social connections with friends and family, to interact with their local community and to engage with special interests" (Dowds et al, 2018, p. 106). Applications such as email, social networking and video calling can be particularly valued by older, often housebound adults, especially in rural areas where barriers of distance and sparse population limit opportunities for social interaction with family and friends. For many older adults visits from health and social care providers are the only regular, in-person, social interactions they have (Farmer et al, 2005) and a balance needs to be struck when considering the suitability of telemedicine or telehealth interventions as an alternative to some, or all, inperson care. For example, interviews with health care providers found support for patients using eHealth but with the caveat that not all patients would benefit or be suitable users of such technology. A participant in the TOPS Welsh case study area told us how much they valued their visits from a social care provider: "I see the carers as really an anchor to reality. These are ordinary bods out there doing things who bring their world into me" (Corbett and Williams, 2014, p. 133). As noted in Philip et al (2015, p. 189) "Replacing face-to face interaction between professionals was viewed negatively, especially for older adults who lived alone and/or did not see other people on a regular basis". Health professionals also observed that to get the most benefit from eHealth in the home the older patient would need to be willing to become ICT literate and able to take some responsibility for their care (for example, to take regular blood pressure readings and send them to the remote monitoring centre). Concomitantly, the TOPS survey of Pain Association members found that nearly two-thirds of respondents were happy in principle to consider using technology in their healthcare, but those who lived alone were less receptive to replacing in-person care with technology than those who lived with at least one other person (Currie et al, 2015).

Collectively the findings from our case studies suggest that many older rural adults are already regular users of digital technologies or are willing to become users, if offered appropriate support. That said, digital interventions appear to hold greater relevance to older adults who live with or have ready access to, either or both, a family member, or informal or formal health and social care support. For the elderly who live alone and/or are more physically isolated in terms of location and support networks, assistance to become familiar and literate with digital devices may be less readily available and a more cautious approach is required. Such adults expressed anxiety that digital technologies could replace some or all of their limited opportunities for inperson social interaction. Such anxiety is not unfounded because it is known that loneliness and a lack of social interaction with others can be detrimental to wellbeing and mental health. Thus in a Smart Village context how quality of life and the health and social care requirements of 
older citizens are addressed will be shaped by household circumstances, the proximity of family members, spatial characteristics of the locality (e.g. distance to services), and the formal and informal health, social care, and assisted living choices available.

\section{Profiling the 'digital services' layer}

As discussed in section 3, digital technologies can be deployed in numerous ways to enhance the lives of older people including to deliver financially sustainable health and social care solutions to support independent living, provide opportunities for social interactions and to give older adults choice or a greater sense of autonomy.

\section{Addressing the challenge of cost-effective quality service provision?}

eHealth digital services have been developed in many national contexts and allow health care professionals to remotely evaluate, diagnose and treat patients via the deployment of various types of digital technology. eHealth applications are attractive to those who plan and manage rural health and social care as they present opportunities to deliver effective and efficient care to dispersed populations. An added attraction is lessening budgetary pressures as compared to care models reliant on in-person delivery of services. However, a recent systematic review noted that "There are few cost-utility and cost-effectiveness studies for ehealth and mhealth systems in the literature. Some cost-effectiveness studies demonstrate that telemedicine can reduce the costs, but not all" (de la Torre- Díez et al, 2015, p. 81). In some remote rural scenarios, digital resources may be the only health care intervention available without patients being required to travel a long distance to a population centre. An example explored in the TOPS project is the UK National Health Service's Pathways through Pain. This online modular programme, which patients can take following a referral from a clinician, includes physiotherapy exercises and other therapies designed to help patients self-manage chronic pain. As reported in Currie et al (2015) TOPS interviewees who had used Pathways through Pain reported that they had been "introduced ... to new relaxation techniques and to new exercises to do at home". Functionality within this eHealth application allowed patients to repeatedly return to selected resource materials such as those demonstrating the correct way to perform specific exercises, a particularly useful attribute for patients who live in remote areas where specialist services such as physiotherapy are rarely located.

\section{Fit for purpose digital services: design provisions}

While the caveats regarding the suitability of eHealth services to individual circumstances are discussed above, decisions about the development and design of digital applications are routinely made outside the rural context, and often overlook the requirements of older adults. As noted by Dodge (2019, p. 37) the rural is often absent from mainstream reporting and analysis of digital technologies with, "a blind spot with regard to consideration of the particular 'impacts' of computerization in rural contexts," and the countryside missing, "in consideration of the social implications of the internet of things". Human-Computer Interaction study guidelines specify that technologies being designed for older people require different functionality to technologies in development for use by other demographic groups. For example, a large font size should be used, the amount of text on screen limited and functions should be simple to navigate (e.g. Doyle et al, 2010). In the TOPS study older adult preference for using a tablet rather than a laptop was expressed because of difficulties some participants had using a touchpad or a 'mouse': touch/swipe screen functions were identified as being much easier to use. Philip et al (2015, p. 189) reported one TOPS participants who said "... because I can't do it with rolling the finder [on a tracker pad], I don't like that - the laptop. So I use the mouse of course but's much, much easier on the iPad". Tablets were also favoured because they were easy to reach if bed-ridden, and easier to use in bed than other devices such as a laptop (Currie et al, 2015). Technologies designed to support social interaction could be inappropriate for use by the hard of hearing who found it difficult to follow conversations if more than two people were participating (ibid, p. 7). 
Many assisted living 'internet of things' devices and eHealth technologies are not innovative per se but their transferability and adaptability to address a new set of circumstances, including providing a new mode of delivering services to older adults in rural areas, has value. However, these proposed solutions need to factor in the cost (to private citizens and public service providers) of owning and running Internet enabled devices and ensure that the technical platform that supports such devices is not frequently updated and rendered unusable in existing devices.

\section{Connecting the parts: moving towards a digital interface}

In Smart Villages older people could be supported if some 'everyday' tasks were administered digitally, with potential for proxy digital activity to replace in-person support. For example, family members living at a distance can now easily submit online grocery shopping orders, request repeat prescriptions or make a health care appointment using an online booking system, activities that once had to be done in person. Family members can be given permission to access the instructions elderly relatives give to hands-free, voice-controlled devices via transcripts of conversations forwarded to a linked smart phone. A key issue in assessing the potential of such approaches to assisted living among the elderly in rural areas is the presence (albeit at a distance) and involvement of known and trusted third parties. Commonly these are immediate family members but what would be suitable for those with no close family or friends? This is a challenge the Tribe digital platform and ongoing pilot study is seeking to address by identifying and addressing the breadth and depth of needs within a local community through an active citizenship approach. Through geo-spatial mapping of community need, connecting 'big data' about adult social care, healthcare and voluntary services, a needs spectrum is generated. From this, areas of demand are identified, as are the potential resources to meet those demands. To facilitate a suitable match of identified demand (need) to supply (choice and access to appropriate and flexible services), a Community Catalyst Coordinator is employed to work in the community 'on the ground'. The Tribe digital platform also provides a portal through which those in need of support and/or personal care can request such support from vetted, trusted community members and those who wish to supply assistance, be they a volunteer, personal care provider and/or micro-enterprises. As such, the Tribe digital platform becomes an interface between the society and services layers of the digital ecosystem and has the potential to develop further into an organisation ecosystem that offers a means of supporting independent living in rural contexts.

\section{The 'society' and 'digital services' interface}

The interface between 'society' and 'digital services' is clearly contingent on other components of the digital ecosystem. The question for how healthy ageing in Smart Villages could be supported is therefore how to integrate the society-digital services requirements and possibilities within the parameters of what is feasible in respect of both 'infrastructure' and 'technical platform' layers.

\section{Addressing digital divides}

The mediating role of adequate broadband infrastructure and mobile phone connectivity is implicit in each of the case studies referred to in this paper. For example, in Scottish-based fieldwork for TOPS, a health care professional told us about a telehealth trial they had been involved with that required patients to take regular readings using a monitoring device that were then to be sent to a central monitoring service. On the ground difficulties were experienced because the telehealth device "can't connect to the phone lines, although it can take the data, it can't transmit it back". A patient and their spouse who were interviewed in the TOPS project described how frustrating the spouse's attempts to access web pages with medical information for their partner were because their broadband was poor: "... a problem here is that the internet is so slow so you've got to have time to sit and let it - it can take two or three minutes for a page to load ..." (Currie et al, 2015, p. 8). These two TOPS examples show that while patients and health care providers were willing and able to use smart technologies their efforts were thwarted, and the potential benefits of the technologies they were trying to use could not be 
achieved, because of inadequacies in the telecommunications infrastructure serving their remote homes. Inadequate digital infrastructure continues to be common in remote rural areas and represents a structural barrier to enhanced deployment of digital technologies in many domains of life.

In a more everyday context the increasing push for online modes of service delivery to be the norm poses difficulties for those who live in areas where fixed and/or mobile connectivity is inadequate. In the UK private sector utilities suppliers expect customers to manage their account online. The closure of many bank branches across the UK has been acutely felt in rural areas where it is not uncommon for there to be no physical banking presence, especially in remote rural areas. Many rural consumers, irrespective of age, have no choice but to use online banking applications. The push to online by default, and sometimes online only service delivery has paid little, if any, attention to catering for the needs of older adults and others who do not have digital skills or the ability to meet the costs of being digitally engaged (for example, through ownership of digitally enabled devices and payment of a broadband contract). The inadequacies of digital connectivity in many remote rural areas has likewise been overlooked by organisations and agencies pushing citizens to be 'digital by default.' Convenience to the user, efficiency and cost-effectiveness are cited goals of this prevailing context for public service provision in the UK, yet "a misalignment of digital connectivity policy aspirations and the realities of broadband services availability" is a dilemma that is still manifest in a number of ways (Williams et al, 2016, p. 772). The ENRD (2018, p. 38) note that "the availability of adequate digital infrastructure is a necessary but not sufficient condition for digital innovation in smart villages". We argue, however, that adequate digital infrastructure is essential. The efforts of many rural communities across Europe, in particular remote and sparely populated areas, to develop digitally supported pathways for innovative solutions to rural challenges will continue to be thwarted unless their digital infrastructure is improved. This will require further investment but, to date, no additional European funding for digital infrastructure has been made available to drive forward Smart Village ambitions. Relatedly, without adequate connectivity, it will be difficult to incentivise more older rural adults to develop digital skills and become confident, regular users of digital services and applications.

Nowhere is this more apparent than in the Tribe Community Catalyst pilot study in Shropshire. Its approach illustrates a mix of digital and human-led process, that is challenging and complex in practice, but demonstrates significant potential. The selection of the pilot study area - three 'chunky villages' in North Shropshire, was on the basis of the presence of a critical mass of population, villages where there were identified challenges for older adults in accessing care packages, and the presence of adequate digital infrastructure to support access to Tribe. In this pilot venture, the impact of the facets of rural digital divides, including infrastructure, uptake and literacy, are yet to be ascertained. There is, however, little doubt that in the more remote, and less populated south-west of Shropshire, a Tribe pilot would have proved problematic, given insufficient broadband and mobile phone coverage. Thus while Tribe provides a timely opportunity to explore and intervene in respect of issues relating to issues of digital uptake and literacy, particularly among those who have little or no access to family support, the Tribe platform remains dependent on the resident population having access to 'fit for purpose' mobile and fixed internet infrastructure.

\section{Conclusion}

We have provided evidence from the UK context that suggests that the Smart Village concept has considerable potential to promote and support healthy, active and independent ageing. In the UK, where rates of adoption of digital technologies by older adults is much higher than in many other European nations, there is a demonstrated willingness amongst older rural adults to use various digital technologies and applications that support individual and community wellbeing. This willingness is commonly underpinned by older adults having both the means and personal motivation(s) to participate in the digital society, although in some contexts there is an element of coercion at play whereby older citizens have been 'pushed' into adopting online services as other modes of delivery are withdrawn. If the behaviour of older rural adults in the UK is replicated in the future across other European nations where current rates of Internet 
use amongst older rural populations are lower, digitally enabled Smart Village ambitions could become integral to responses to rural demographic ageing. Despite the considerable opportunities presented by digital technologies and applications, Smart Villages as environments for healthy ageing cannot be fully developed without better understanding of the society - digital services interface and the digital divides that characterise many areas of rural Europe.

The illustrative examples drawn from our case studies are indicative of ways in which digital technologies are already being exploited by older adults. Use of eHealth devices and healthcare related online applications is already widespread. However, despite a willingness to use digital technologies, and a contracting generational gap in Internet use, there remain barriers to exploiting the full potential of smart developments in a rural context. These compromise the extent to which digital solutions to rural challenges, those associated with demographic ageing and others, can be further developed. Three key barriers were highlighted through revisiting the TOPS and Rural PAWS case studies and by examining the ongoing work in the Tribe Community Catalyst study.

Firstly, in an increasingly digital society and economy it is often assumed that digital solutions are the answer to most, if not all, societal challenges. In a rural context, and more specifically a remote rural context, digital technologies have the potential to revolutionise many dimensions of personal lives, economic activity and the delivery and consumption of a wide range of public and private sector goods and services. As well as helping to transcend difficulties associated with sparsity of population and remoteness, switching to digital modes of service delivery could cut costs for service providers. However, digital modes are not always appropriate. For example, some health care requires physical contact between patient and health professional, other care does not and could potentially be substituted with an eHealth intervention, although as health professionals in the TOPS project articulated, if in-person interaction is diminished other aspects of wellbeing could be compromised. Some older adults find it difficult to use digitally enabled devices due to a physical impairment or cannot afford to own and operate an Internet-enabled device and thus cannot undertake online tasks even if they want to. Proxy internet use can address this barrier, but not all older adults have a trusted third party they can turn to. Smart developments in village/rural community and other contexts should, we suggest, be sensitive to the fact that wholly digital solutions are not appropriate in all individual circumstances. To overlook this barrier could lead, inadvertently, to the exclusion of a minority of older adults, likely to include those who are already amongst the most vulnerable.

Secondly, an urban-led digital economy and society commonly assumes that all citizens are Internet users and that everyone has access to fast and reliable fixed and/or mobile telecommunications infrastructure. As we and others have evidenced (c.f. Philip et al, 2015; 2017) this is not the case, with a territorial urban-rural digital divide persisting despite considerable sums of public money being invested worldwide in upgrading national digital telecommunications infrastructure. Remote rural areas in the UK and elsewhere are already lagging behind in terms of their digital infrastructure and are at risk of being further marginalised as investment focuses on large population centres and areas with a large enough population for commercial telecommunications providers to provide a profitable service. Geographical areas that could potentially derive most benefit from digital developments, such as remote rural areas, and citizens who live in the smallest settlements and in isolated dwellings are most at risk of being left behind in the switch to digital. Further depopulation of remote rural areas is a real possibility if digital infrastructure limitations are not addressed. The ENRD (2018) acknowledge that rural digital infrastructure across Europe needs to be improved but, as we have noted above, good digital telecommunications infrastructure is essential, not simply desirable, if Smart Village aspirations are to be met. Without a fit for purpose infrastructure layer, a fit for purpose digital ecosystem cannot be developed.

The third challenge is aligned with the rapid pace of change in digital landscapes. Each innovation or iteration of devices and application presents further scope for rural residents, patients, social enterprises and businesses to fall behind, due to questions surrounding device maintenance, upskilling, data storage, capacity, and security. For example, if older adults invest in a digital device they do not want it to be rendered unusable if, soon after purchase, changes 
to the technical platform to which it is linked renders their device incompatible with the system it was designed to operate within.

The three overarching challenges to realising smart communities as presented may apply in urban and rural contexts. Promoting inclusive approaches and user informed design and functionality of technologies intended to support health ageing are a-spatial considerations. Yet the remote rural context brings added layers of complexity to achieving Smart Villages/smart rural territories that can support healthy ageing in place. Smart Villages offer a positive, forwardlooking path for rural communities to follow providing that lessons learnt from previous digital rural research are incorporated into the smart solutions being developed now and in the future.

\section{Acknowledgements}

The TOPS and Rural PAWS projects were funded by an award made by the RCUK Digital Economy programme to the dot.rural Digital Economy Hub, award reference EP.G066051/1.

Involvement with the Tribe project is facilitated through the ERDF funded Centre for Research in the Environment, Science and Technology, CREST@UCS.

Academic references

[1] Angelidou, M. (2015). Smart cities: a conjecture of four forces. Cities, 47, 95-106. DOI: 10.1016/j.cities.2015.05.004.

[2] Ash, J., Kitchin, R. \& Leszczynski, A. (2019). Introducing Digital Geographies. In Ash, J., Kitchin, R. \& Leszczynski, A., eds., Digital Geographies. (pp.1-10). London: Sage.

[3] Ash, J., Kitchin, R. \& Leszczynski, A. (2018). Digital turn, digital geographies? Progress in Human Geography, 42(1) 25-43. DOI: 10.1177/0309132516664800.

[4] Caprotti, F. \& Cowley, R. (2019). Varieties of smart urbanism in the UK: Discursive logics, the state and local urban context. Transactions of the Institute of British Geographers 44(3), 587-601. DOI: 10.1111/tran.12284.

[5] Caragliu, A., Del Bo, C. \& Nijkamp, B. (2011). Smart Cities in Europe. Journal of Urban Technology 18(2) 65-82. DOI: 10.1080/10630732.2011.601117.

[6] Corbett, S. \& Williams, F. (2014) Striking a professional balance: interactions between nurses and their older rural patients British Journal of Community Nursing 19(4), 162-167. DOI: 10.12968/bjen.2014.19.4.162.

[7] Currie, M., Philip, L., Roberts, A. (2015). "I don't mind it, but it can take over, it can make things over-complicated..." Attitudes towards, use and acceptance of technology in rural healthcare: a case study of rural adults living with chronic pain. BMC Health Services Research 15:162. DOI 10.1186/s12913-015-0825-0

[8] Dodge, M. (2019). Rural. In: Ash, J., Kitchin, R. \& Leszczynski, A., eds., Digital Geographies (pp.36-48). London: Sage.

[9] Dowds, G., Philip, L. J., \& Currie, M. (2018). A window to the outside world: digital technologies and new possibilities for involving rural housebound older adults in local social activities. In Curl, A. \& Musselwhite, C., eds., Geographies of transport and ageing (pp. 101-132). Basingstoke: Palgrave Macmillan.

[10] Doyle, J., Skrba, Z., McDonnell, R. \& Arent, B. (2010). Designing a Touch Screen Communication Device to Support Social Interaction Amongst Older Adults. In McEwan, T. \& McKinnon, L., eds., Proceedings of the 2010 British Computer Society Conference on Human-Computer Interaction, \{BCS-HCI\} 2010, Dundee, United Kingdom, 6-10 September 2010 (pp. 117-185). London: BCS, The Chartered Institute for IT. DOI: 10.14236/ewic/HCl2010.23. 
[11] Jong, M. de, Joss, S., Schraven, D., Zhan, C. \& Weijnen, M. (2015). Sustainable - smart resilient - low carbon - eco - knowledge cities; making sense of a multitude of concepts promoting sustainable urbanization. Journal of Cleaner Production 109, 25-38. DOI: 10.1016/j.jclepro.2015.02.004.

[12] König, R., Seifert, A. \& Doh, M. (2018). Internet use among older Europeans: an analysis based on SHARE data. Universal Access in the Information Society 17(3), 621-633. DOI: 10.1007/s10209-018-0609-5.

[13] Luque-Ayala, A. (2019). Urban. In Ash, J., Kitchin, R. \& Leszczynski, A., eds., Digital Geographies (pp. 24-35). London: Sage.

[14] Mort, A. \& Philip, L. (2014). Social isolation and the perceived importance of in-person care amongst rural older adults with chronic pain: a review and emerging research agenda. Journal of Pain Management 7(1), 13-22.

[15] Naldi, L., Nilsson, P., Westlund, H. \& Wixe, S. (2015). What is smart rural development? Journal of Rural Studies 40, 90-101. DOI: 10.1016/j.jrurstud.2015.06.006.

[16] Nilssen, M. (2019). To the smart city and beyond? Developing a typology of smart urban innovation. Technological Forecasting and Social Change, 142, 98-104. DOI: 10.1016/j.techfore.2018.07.060.

[17] Peters, D. J., Hamideh, S., Eman Zarecor, K. \& Ghandour, M. (2018). Using entrepreneurial social infrastructure to understand smart shrinkage in small towns. Journal of Rural Studies 64, 39-49. DOI: 10.1016/j.jrurstud.2018.10.001.

[18] Philip, L., Roberts, A., Currie, M. \& Mort, A. (2015). Technology for Older adults: maximising Personal and Social interaction (TOPS): exploring opportunities for eHealth to support the older rural population with chronic pain. Scottish Geographical Journal 131(34), 181-193. DOI 10.1080/14702541.2014.978806.

[19] Philip, L. J. \& Williams, F. (2019). Remote rural home based businesses and digital exclusion: understanding needs and expectations in a digitally underserved community Journal of Rural Studies 68, 306-318. DOI: 10.1016/j.jrurstud.2018.09.011.

[20] Philip, L. J., Cottrill, C. \& Farrington, J. (2015). 'Two-speed' Scotland: patterns and implications of the digital divide in contemporary. Scotland Scottish Geographical Journal 131(3-4), 148-170. DOI: 10.1080/14702541.2015.1067327.

[21] Philip, L. J., Cottrill, C., Farrington, J., Williams, F. \& Ashmore, F. (2017). The digital divide: patterns, public policy and options for connecting the 'final few' in rural communities across Great Britain. Journal of Rural Studies 54, 386-398. DOI: 10.1016/j.jrurstud.2016.12.002.

[22] Philip, L, Brown, D. \& Stockdale, A. (2012). Demographic ageing in rural areas: insights from the UK and US. In Shucksmith, M., Brown, D., Warner, M., Vergunst, J. \& Shortall, S., eds., Rural Transformations and Policies in the UK and US (pp. 58-78). London: Routledge.

[23] Salemink, K., Strijker, D. \& Bosworth, G. (2017). Rural development in the digital age: a systematic literature review on unequal availability, adoption and use in rural areas. Journal of Rural Studies 54, 360-371. DOI: 10.1016/j.jrurstud.2015.09.001.

[24] Torre-Díez, I. de la, López-Coronado, M., Vaca, C., Aguado, J. S. \& de Castro, C. (2015). Cost-Utility and Cost-Effectiveness Studies of Telemedicine, Electronic, and Mobile Health Systems in the Literature: A Systematic Review. Telemedicine Journal and e-Health 21(2), 81-85. DOI: 10.1089/tmj.2014.0053.

[25] Visvizi, A. \& Lytras, M. D. (2018). It's Not a Fad: Smart Cities and Smart Villages Research in European and Global Contexts. Sustainability 10(8), 2727. DOI: 10.3390/su10082727.

[26] Williams, F., Farrington, J. \& Philip, L. J. (2015). 'It's revolutionised how we do things': then and now - a case study of Internet behaviours in a remote rural community. In Sutherland, 
L-A. et al., eds., Places of Possibility? Rural Societies in a Neoliberal World (pp. 203-204). Aberdeen: the James Hutton Institute.

[27] Williams, F., Philip, L. J., Farrington, J. \& Fairhurst, G. (2016). 'Digital by Default' and the 'hard to reach': exploring solutions to digital exclusion in remote rural areas. Local Economy 31(7), 257-777. DOI: 10.1177/0269094216670938.

[28] Zavratnik, V., Kos, A. \& Stojmenova, E. (2018). Smart Villages: Comprehensive Review of Initiatives and Practices. Sustainability 10(7), 2559. DOI: 10.3390/su10072559.

\section{Other sources}

[29] Community Catalysts C.I.C. (2019). We are Community Catalysts. Available at https://www.communitycatalysts.co.uk/.

[30] European Commission (2016). Cork Declaration 2.0 A Better Life in Rural Areas. Available at https://ec.europa.eu/agriculture/sites/agriculture/files/events/2017/cork-declarationberlin/cork-declaration-2-0_en.pdf.

[31] European Commission (2017). EU Action for Smart Villages. Released 11 April 2017. Available at https://ec.europa.eu/agriculture/sites/agriculture/files/rural-development-20142020/looking-ahead/rur-dev-small-villages_en.pdf.

[32] European Commission (2018a). Creating a Digital Society. Released 4 July 2018. Available at https://ec.europa.eu/digital-single-market/en/policies/creating-digital-society.

[33] European Commission (2018b). Policies for Ageing Well with Information and Communication Technologies (ICT). Updated 1 October 2018. Available at https://ec.europa.eu/digital-single-market/en/policies/ageing-well-ict.

[34] European Network for Rural Development (2018). Smart Villages Revitalising Rural services, EU Rural Review no 26, May 2018 (English language version). Available at https://enrd.ec.europa.eu/publications/eu-rural-review-26-smart-villages-revitalising-ruralservices_en.

[35] European Network for Rural Development (2019a). How to support Smart Villages strategies which effectively empower rural communities. Orientations for policy makers and implementers. Available at

https://www.google.com/url?sa=t\&rct=j\&q=\&esrc=s\&source=web\&cd=1\&cad=rja\&uact=8\&v ed=2ahUKEwjl4sDDzZHIAhWpTRUIHeNBDDUQFjAAegQIAhAC\&url=https\%3A\%2F\%2Fe nrd.ec.europa.eu\%2Fsites\%2Fenrd\%2Ffiles\%2Fenrd_publications\%2Fsmart-

villages_orientations_sv-strategies.pdf\&usg=AOvVaw2p1f2rdZABCNQmxI7rptil.

[36] European Network for Rural Development (2019b). Smart Villages - how to ensure that digital strategies benefit rural communities. Orientations for policy-makers and implementers. Available at

https://www.google.com/url?sa=t\&rct=j\&q=\&esrc=s\&source=web\&cd=1\&ved=2ahUKEwjUy 7GqzZHIAhUrURUIHcDdCMUQFjAAegQIABAC\&url=https\%3A\%2F\%2Fenrd.ec.europa.eu $\% 2$ Fsites\%2Fenrd\%2Ffiles\%2Fenrd_publications\%2Fsmart-villages_orientations_digitalstrategies.pdf\&usg=AOvVaw2vHI5JfoKe1AXUcr1MB1ih.

[37] Eurostat (2017). "A look at the lives of the elderly in the EU today". Available at https://ec.europa.eu/eurostat/cache/infographs/elderly/index.html.

[38] Eurostat (2019). "Population structure and ageing". Available at https://ec.europa.eu/eurostat/statistics-

explained/index.php/Population_structure_and_ageing\#Past_and_future_population_agein g_trends_in_the_EU.

[39] Gov.UK Digital Marketplace (n.d.) TRIBE: Social Action and Community Capacity. Available at https://www.digitalmarketplace.service.gov.uk/g-cloud/services/547085449955561. 
[40] Howells, R. (2018). The Tribe Project. Available at https://www.tribeproject.org/static/tribebrochure.pdf.

[41] Nieto, E. (2019). Smart Villages: A new concept for rural development. Available at https://www.scitecheuropa.eu/smart-villages-rural-development/95112/.

[42] Office for National Statistics (2018). Statistical Bulletin Internet users, UK: 2018. Internet use in the UK annual estimates by age, sex, disability and geographical location. Released 31 May 2018.

[43] Pilot Project on Smart Eco-Social Villages (2019). Smart Village Pilot Project Briefing Note, February 2019. Available at https://www.google.com/url?sa=t\&rct=j\&q=\&esrc=s\&source=web\&cd=1\&ved=2ahUKEwiX5 ZePzZHIAhXsVRUIHW1fD3cQFjAAegQIABAC\&url=https\%3A\%2F\%2Fdigiteventimages.s3.amazonaws.com\%2F5c0e6198801d2065233ff996-registrationfiletexteditor1551115459927-smart-villages-briefingnote.pdf\&usg=AOvVaw0v5ZDpt4Xp0Vp9GG_vZIsH.

[44] Scottish Government (2018). Percentage age distribution of Population by Geographic Area, 2016, Equality Evidence Finder, Summary Rural and Environment. Available at https://www2.gov.scot/Topics/People/Equality/Equalities/RuralEnvironment.

[45] Soto, P. \& Nieto, E. (2019). Rural Dialogues|Smart Villages - Turning Momentum into Support for Local Action Agricultural and Rural Convention, 15th July, 2019. Available at http://www.arc2020.eu/rural-dialogues-smart-villages-turning-momentum-support-localaction/.

[46] Tribe (2018). The Tribe Project. Available at https://www.tribeproject.org/.

[47] World Health Organisation (2019). What is healthy ageing? Available at https://www.who.int/ageing/healthy-ageing/en/. 